\title{
ANATOMIA DO LENHO DE DUAS ESPÉCIES DE CROTON (EUPHORBIACEAE) DO RIO GRANDE DO SUL ${ }^{1}$
}

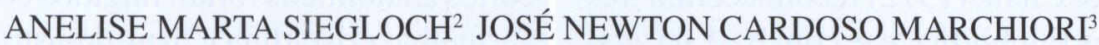 \\ SIDINEI RODRIGUES DOS SANTOS ${ }^{4}$
}

\section{RESUMO}

O presente estudo descreve a estrutura do xilema secundário de Croton dracunculoides e Croton pycnocephalus, com base em material procedente do Rio Grande do Sul. A descrição anatômica segue IAWA (1989). Ambas as espécies apresentam: poros em múltiplos radiais; placas de perfuração simples; pontoações areoladas pequenas; parênquima paratraqueal-escasso; raios exclusivamente unisseriados, heterogêneos e com células perfuradas; e fibrotraqueídeos de paredes finas. A distinção anatômica de ambas as espécies pode ser feita com base no comprimento de vasos e fibras, bem como pela presença de cristais em Croton dracunculoides.

Palavras-chave: Anatomia da Madeira, Croton dracunculoides, Croton pycnocephalus, Euphorbiaceae.

\section{ABSTRACT}

[Wood anatomy of two Croton species (Euphorbiaceae) from Rio Grande do Sul State (Brazil)]. The wood anatomy of Croton dracunculoides and Croton pycnocephalus are presently described, based on materials from Rio Grande do Sul state (Brazil). The anatomical descriptions follows IAWA (1989). Both species presented: radial multiple pores; simple perforation plates; small bordered pits; paratracheal scanty axial parenchyma; uniseriate and heterogeneous rays, with perforated cells; and thin walled fibertraqueids. Both species can be set apart by vessel and fiber sizes, as well as the presence of crystals in Croton dracunculoides wood.

Key words: Croton dracunculoides, Croton pycnocephalus, Euphorbiaceae, Wood Anatomy.

\section{INTRODUÇÃO}

A família Euphorbiaceae apresenta hábitos extraordinariamente variados, incluindo ervas, arbustos, árvores e lianas, geralmente com látex branco e por vezes espinescentes, de aspecto áfilo, à semelhança de Cactáceas (Schultz, 1943; Souza \& Lorenzi, 2008).

O gênero Croton L. abrange 1.300 espécies (Judd et al., 2009), distribuídas nas regiões tropicais e subtropicais de ambos os hemisférios, notadamente no continente americano (Baci-

1 Recebido para publicação em 14/06/2011 e aceito para publicação em 30/06/2011.

2 Mestranda do Curso de Pós-Graduação em Engenharia Florestal. Bolsista - CAPES. Universidade Federal de Santa Maria, CEP 97105-900. Santa Maria, RS, Brasil. anesiegloch@yahoo.com.br

3 Engenheiro Florestal, Dr. Bolsista de Produtividade em Pesquisa (CNPq - Brasil). Professor Titular do Departamento de Ciências Florestais, Universidade Federal de Santa Maria. Santa Maria, RS, Brasil.

${ }^{4}$ Biólogo, Dr. Núcleo de Estudos Botânicos Balduino Rambo, UFSM. galupo, 2005). Para o Rio Grande do Sul, Allem (1978) refere 38 espécies nativas, entre as quais Croton dracunculoides e C. pycnocephalus, objeto do presente estudo. Ambas as espécies carecem de investigação anatômica sobre a estrutura do lenho.

Arbusto dióico de até 1,5 m de altura, Croton dracunculoides Baill. habita tanto solos arenosos como rochosos, no sudeste e sudoeste do Rio Grande do Sul, alcançando, provavelmente, o Uruguai (Allem, 1978).

Arbusto de até $2 \mathrm{~m}$ de altura e com denso indumento dourado nas partes vegetativas, Croton pycnocephalus Baill. habita solos arenosos, em capoeiras e campos rupestres no nordeste do Rio Grande do Sul, alcançando a Argentina e, provavelmente, o Uruguai e Paraguai (Allem, 1978).

O gênero Croton, apesar de numeroso, foi pouco estudado sob o ponto de vista anatômico, dispondo a literatura de escassas referências, 
inclusive sobre espécies de potencial madeireiro.

Metcalfe \& Chalk (1972) reconheceram três grupos para as Euphorbiaceae com base na anatomia do lenho. Vinculado às Crotonoideae, são citadas as seguintes características para o gênero Croton: placas de perfuração simples; pontoações intervasculares médias a grandes; pontoações raio-vasculares grandes e alongadas (frequentemente escalariformes) ou semelhantes às intervasculares; elementos vasculares de comprimento médio a moderadamente curto; parênquima abundante, apotraqueal difuso ou em faixas contínuas, com 1-2 células de largura; séries parenquimáticas de 8 células $(4$, em algumas espécies); raios com 2-3 células de largura ou exclusivamente unisseriados, por vezes com 4-5 células de largura; raios marcadamente heterogêneos, frequentemente com 10 ou mais fileiras marginais de células eretas e mais de 1 parte multisseriada por raio, por vezes com espaços intercelulares; fibras de paredes finas a moderadamente espessas, de comprimento médio a moderadamente curto, com pontoações simples ou aréolas pequenas, por vezes distintas; e tubos laticíferos ocasionais, nos raios.

\section{MATERIAL E MÉTODOS}

No presente estudo foram analisadas duas amostras de madeira:

- Croton dracunculoides Baill. Marchiori, J.N.C, n. 831. Bagé (RS), BR 153, km 530, 07 08-1987.

- Croton pycnocephalus Baill. Marchiori, J.N.C, n. 809. Jaguarizinho, Jaguari (RS), 2507-1987.

Para a confecção das lâminas histológicas foram extraídos três corpos de prova $(1 \times 2 \times 3 \mathrm{~cm})$ da parte mais externa do lenho, próxima ao câmbio, para cada uma das amostras, orientados para a obtenção de cortes nos planos transversal, longitudinal radial e longitudinal tangencial. Outro bloquinho foi também retirado, com vistas à maceração.

A confecção das lâminas histológicas seguiu a metodologia descrita em Burger \& Richter
(1991). No preparo de lâminas de macerado usou-se o método de Jeffrey (Freund, 1970). Os cortes anatômicos foram tingidos com acridinavermelha, crisoidina e azul-de-astra (Dujardin, 1964); o macerado, apenas com safranina (1\%). Na montagem das lâminas permanentes usouse Entellan.

As descrições basearam-se nas recomendações do IAWA Committee (Wheeler et al., 1989). No caso da percentagem dos tecidos foram realizadas 600 determinações ao acaso, com auxílio de contador de laboratório, conforme proposto por Marchiori (1980). A abundância de poros foi obtida a partir de um quadrado de área conhecida, superposto a fotomicrografias de seções transversais da madeira.

As medições foram realizadas em microscópio Carl Zeiss, no Laboratório de Anatomia da Madeira da Universidade Federal de Santa Maria. Nas características quantitativas, os números entre parênteses equivalem aos valores mínimos e máximos observados; o valor que acompanha a média é o desvio padrão. As fotomicrografias foram tomadas em microscópio Olympus CX40, equipado com câmera digital Olympus Camedia c3000, no Laboratório de Anatomia da Madeira da Universidade Federal do Paraná.

\section{DESCRIÇÕES ANATÔMICAS}

\section{1 - Croton dracunculoides Baill.}

Anéis de crescimento: marcados por delgada camada de fibras radialmente estreitas e por camada concêntrica de fibras gelatinosas no lenho inicial (Figura 1A,B).

Vasos: muito numerosos $(89 \pm 21,3(67-$ 116) poros $/ \mathrm{mm}^{2}$ ), ocupando $15,8 \pm 3,9 \%$ do volume da madeira. Porosidade difusa. Poros em múltiplos radiais e racemiformes de 2-9 unidades, menos comumente solitários, de seção circular ou oval $(54 \pm 9,4(32,5-68) \mu \mathrm{m}) \mathrm{e}$ paredes espessas $(4,1 \pm 0,8(2,5-6,2) \mu \mathrm{m})(\mathrm{Fi}-$ gura $1 \mathrm{~A}, \mathrm{~B})$; conteúdo, frequente. Elementos vasculares de comprimento médio $(529 \pm 107,4$ $(330-720) \mu \mathrm{m})$, com placas de perfuração sim- 

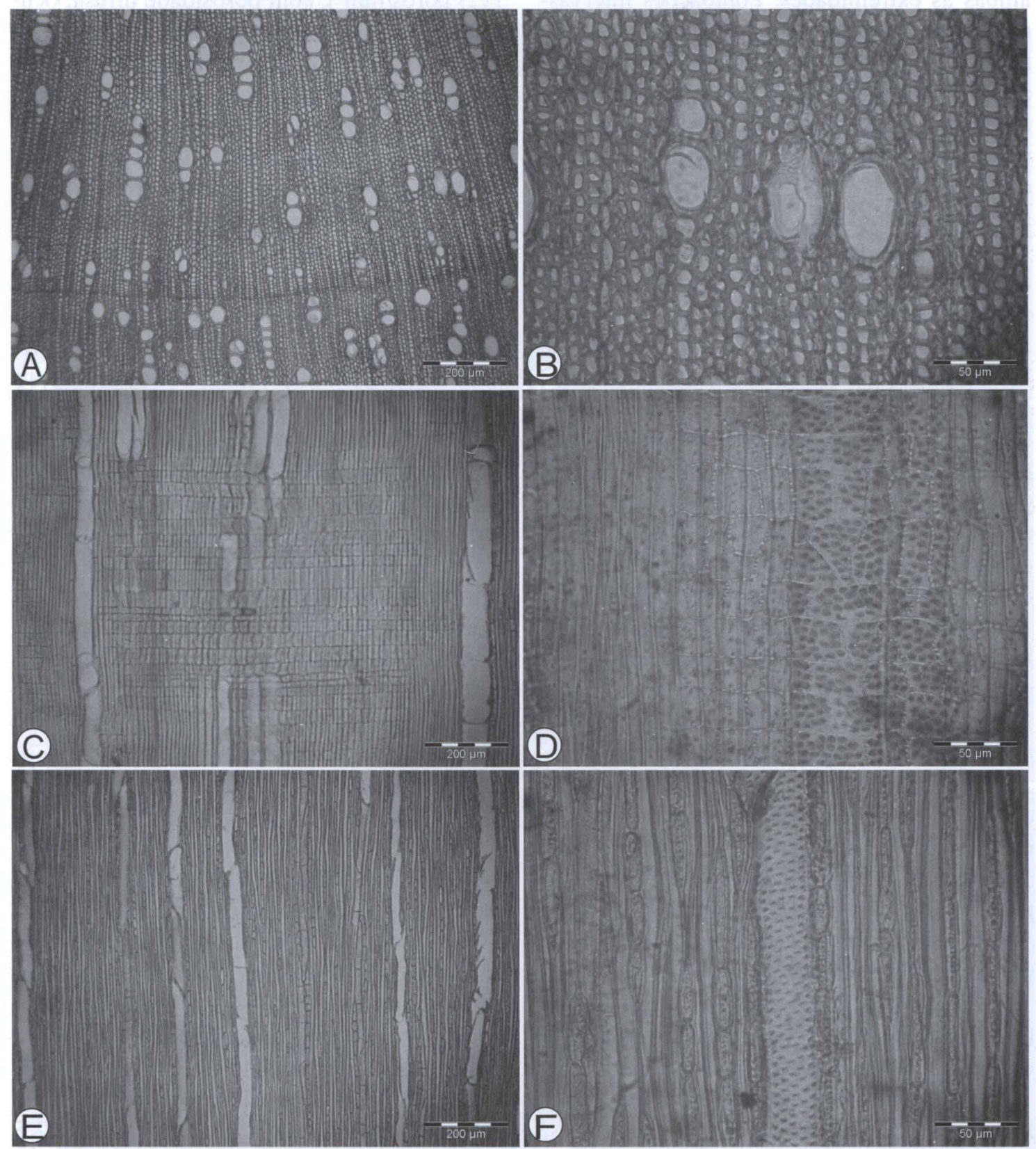

FIGURA 1 - Aspectos anatômicos da madeira de Croton dracunculoides Baill. A - Limite de anel de crescimento, porosidade difusa, poros em múltiplos radiais, racemiformes e solitários (seção transversal). B - Mesma seção, em maior aumento, destacando poros em múltiplos radiais e solitários, parênquima paratraqueal-escasso e fibras de paredes finas. C - Raio heterogêneo, em seção longitudinal radial, com células eretas e quadradas, eventualmente procumbentes, além de células perfuradas de raio e elementos vasculares com placas de perfuração simples. D - Seção longitudinal radial, em maior aumento, mostrando pontoações raio-vasculares alternas, com aréolas distintas e parte de raio com células eretas e quadradas. E-Aspecto da seção longitudinal tangencial, com elementos vasculares, raios exclusivamente unisseriados, parênquima axial seriado e fibras. F - Vasos com pontoações intervasculares alternas, circulares, raios unisseriados e fibras (seção longitudinal tangencial). 
ples e apêndices curtos a longos, em uma ou em ambas as extremidades. Pontoações intervasculares pequenas $(5,4 \pm 0,5(5,2-6,2) \mu \mathrm{m})$, alternas e circulares, por vezes coalescentes, com abertura em fenda elíptica, cruzada, inclusa, não ornamentada (Figura 1F). Pontoações raiovasculares areoladas, com abertura em fenda elíptica $(4,8 \pm 0,5(5,2-6,2) \mu \mathrm{m})$. Espessamentos espiralados, ausentes.

Parênquima axial: representando $3,8 \pm 1,5 \%$ do volume da madeira; em arranjo paratraquealescasso (Figura 1A,B). Séries parenquimáticas de $324 \pm 72(200-508) \mu \mathrm{m}$ de altura, compostas de 2-4 (6) células (Figura 1F).

Raios: muito numerosos $(33 \pm 2,2(30-37)$ raios $/ \mathrm{mm}$ ) e exclusivamente unisseriados, ocupando $19,3 \pm 1,5 \%$ do volume da madeira (Figura $1 \mathrm{E}, \mathrm{F})$. Compostos de células eretas ou eretas e quadradas, com eventuais células curtamente procumbentes, apresentam escassos cristais romboédricos, e medem $528 \pm 257$ (160 - 1150) $\mu \mathrm{m}$ de altura, com 3-27 células. Células radiais de paredes disjuntas e células perfuradas de raio, presentes; conteúdo, ausente. Raios axialmente fusionados, raios agregados e células envolventes, ausentes.

Fibras: com pontoações areoladas maiores do que $3 \mu \mathrm{m}$ e aberturas em fendas elípticas, cruzadas nas faces radiais da parede; curtas (864 $\pm 93,4(600-1000) \mu \mathrm{m})$, de $13 \pm 2,9(10-18)$ $\mu \mathrm{m}$ de largura, de paredes finas $(4 \pm 0,7(2,5-$ 5) $\mu \mathrm{m})$ e seção frequentemente retangular, ocupando $61 \pm 5,9 \%$ do volume da madeira (Figura 1B). Fibras gelatinosas, em faixas concêntricas (Figura 1A,B). Fibras septadas, espessamentos espiralados e traqueídeos, ausentes.

Outros caracteres: variantes cambiais, tubos laticíferos e taniníferos, canais intercelulares, células oleíferas, células mucilaginosas e estratificação, ausentes. Máculas medulares e inclusões minerais, presentes.

\section{2 - Croton pycnocephalus Baill.}

Anéis de crescimento, indistintos (Figura 2A,B).
Vasos: muito numerosos $(93 \pm 23,1$ (60 112) poros $/ \mathrm{mm}^{2}$ ), com porosidade difusa, ocupando $17 \pm 4,2 \%$ do volume da madeira; em múltiplos radiais e racemiformes de $2-13$ poros, menos frequentemente solitários, de seção circular ou oval $(49 \pm 8,4(35-68) \mu \mathrm{m})$ e paredes espessas $(4,8 \pm 0,9(3,7-6,2) \mu \mathrm{m})$ (Figura 2A,B). Elementos vasculares de comprimento médio (342 $\pm 77,5(240-560) \mu \mathrm{m})$, com placas de perfuração simples, circulares, e apêndices em uma ou em ambas as extremidades. Pontoações intervasculares pequenas $(5,6 \pm 0,5$ $(5,2-6,2) \mu \mathrm{m})$, alternas, circulares, com abertura em fenda elíptica, por vezes cruzada, inclusa, não ornamentada (Figura 2F). Pontoações raio-vasculares areoladas, pequenas $(4,2 \pm 0,3$ $(4,1-5,1) \mu \mathrm{m})$, com abertura em fenda elíptica. Espessamentos espiralados e conteúdos, ausentes.

Parênquima axial: representando $4 \pm 0,7 \%$ do volume da madeira; em arranjo paratraquealescasso (Figura 2A,B). Séries parenquimáticas de $456 \pm 101(300-663) \mu \mathrm{m}$ de altura, compostas de $2-4$ (5) células (Figura $2 \mathrm{~F}$ ).

Raios: muito numerosos $(29 \pm 2,5(24-33)$ raios $/ \mathrm{mm}$ ), exclusivamente unisseriados, ocupando $22 \pm 1,6 \%$ do volume da madeira (Figura $2 \mathrm{E}, \mathrm{F})$; compostos por células eretas e quadradas, eventualmente procumbentes, de $669 \pm$

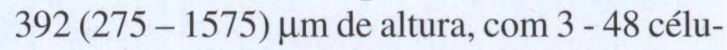
las. Células radiais de paredes disjuntas e células perfuradas de raio, presentes; conteúdos, ausentes. Raios axialmente fusionados, raios agregados, células envolventes e cristais, ausentes.

Fibras: com pontoações areoladas e aberturas em fendas cruzadas, inclusas, maiores do que $3 \mu \mathrm{m}$, nas faces radiais da parede; fibras curtas $(631 \pm 68(500-750) \mu \mathrm{m}), \operatorname{com} 10,4 \pm 2(12,5$ $-20) \mu \mathrm{m}$ de largura, de paredes finas $(2,8 \pm 0,6$ $(2,5-4,4) \mu \mathrm{m})$ e seção frequentemente retangular, ocupando $57 \pm 3,1 \%$ do volume da madeira (Figura 1B). Fibras gelatinosas, em faixas concêntricas. (Figura 2A,B). Fibras septadas, espessamentos espiralados e traqueídeos, ausentes. 

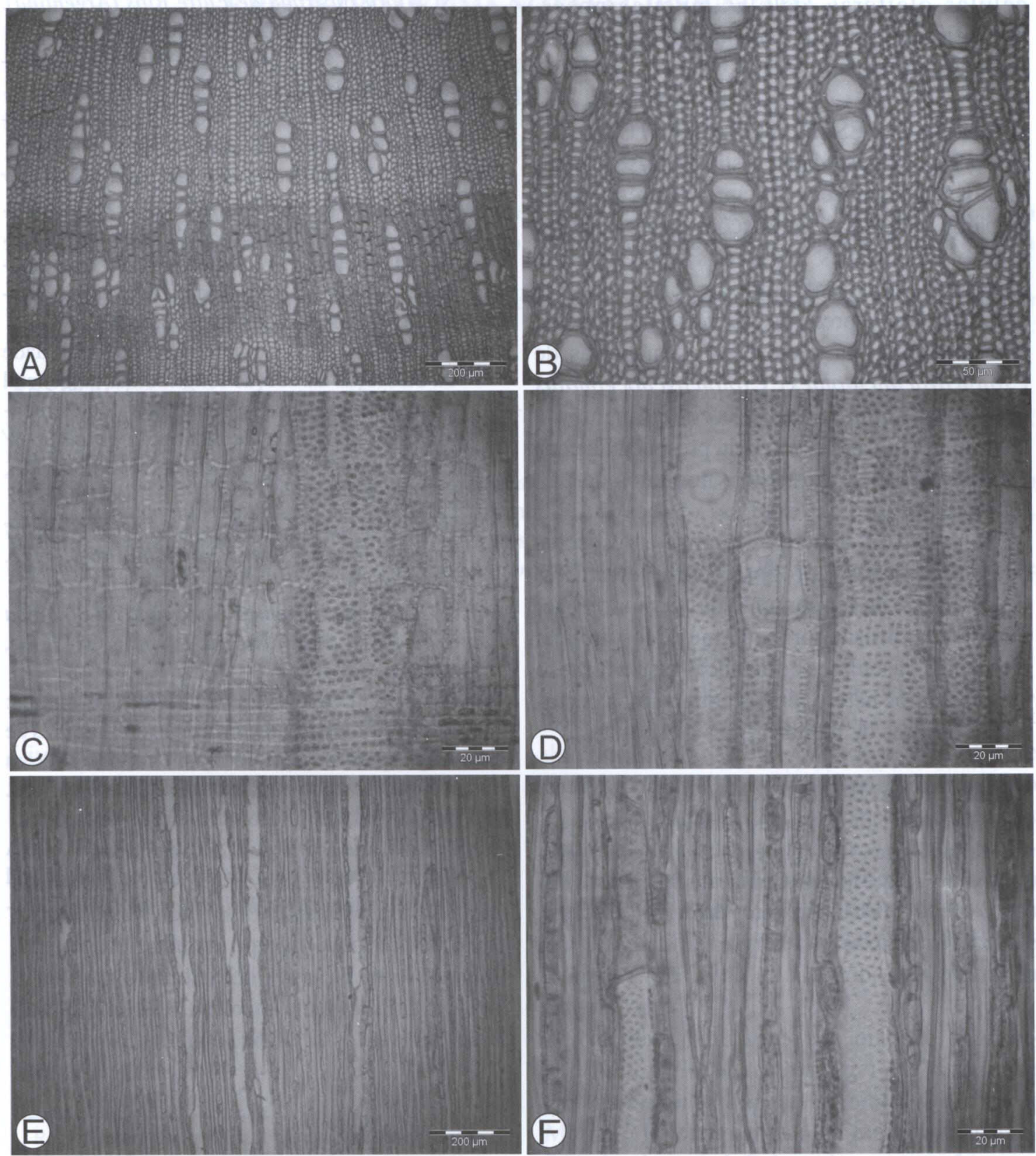

FIGURA 2 - Aspectos anatômicos da madeira de Croton pycnocephalus Baill. A - Seção transversal, mostrando porosidade difusa, poros em múltiplos radiais, menos comumente racemiformes e solitários, e fibras gelatinosas em faixas concêntricas. B - Mesma seção, em maior aumento. C - Raio heterogêneo, em seção longitudinal radial, com células eretas e quadradas, eventualmente procumbentes, e pontoações raio-vasculares areoladas, alternas. D - Mesma seção, destacando células perfuradas de raio e parte de raio com células de paredes disjuntas. E-Aspecto geral da seção longitudinal tangencial, com elementos vasculares, raios unisseriados, parênquima axial seriado e fibras. F - Vasos com pontoações intervasculares alternas, circulares, raios unisseriados e fibras (seção longitudinal tangencial). 
Outros caracteres: variantes cambiais, tubos laticíferos e taniníferos, canais intercelulares, células oleíferas, células mucilaginosas, estratificação, máculas medulares e inclusões minerais, ausentes.

\section{ANÁLISE DA ESTRUTURA ANATÔMICA \\ As espécies estudadas distinguem-se da mai- oria das Euforbiáceas por apresentarem: vasos de paredes espessas; pontoações intervasculares e raio-vasculares pequenas; parênquima paratraqueal-escasso; raios exclusivamente unisseriados; e presença de fibrotraqueídeos. Apesar de similares entre si, as madeiras de Croton dracunculoides e Croton pycnocephalus podem ser distinguidas pelo comprimento de vasos e fibras, bem como pela presença de con- teúdo em vasos e de cristais nos raios da pri- meira das espécies. \\ Nos demais caracteres, ambas as espécies concordam com o proposto por Metcalfe \& Chalk (1972) para o conjunto das Crotonoideae: porosidade difusa; poros em múltiplos radiais; elementos vasculares com placas de perfuração simples; raios heterogêneos com células perfu- radas; e fibras de paredes finas a espessas.}

\section{REFERÊNCIAS BIBLIOGRÁFICAS}

ALLEM, A. C. Preliminares para uma abordagem taxonômica do gênero Croton L. (Euphorbiaceae) no Rio Grande do Sul, Brasil. Boletim do Museu Botânico Municipal, Curitiba, 1978. 339. (Bol. n. 34).
BACIGALUPO, N. M. Euphorbiaceae, Euforbiáceas. In: BURKART, A.; BACIGALUPO, N. M. Flora Ilustrada de Entre Rios (Argentina). Buenos Aires: I.N.T.A., 2005. p. 101-195.

BURGER, L.M.; RICHTER, H.G. Anatomia da Madeira. São Paulo: Ed. Nobel, 1991. 154 p.

DUJARDIN, E.P. Eine neue Holz-Zellulosenfaerbung. Mikrokosmos, n. 53, p. 94, 1964.

FREUND, H. Handbuch der Mikroskopie in der Technik. Frankfurt: Umsham Verlag, 1970. 375 p.

JUDD, W. S.; CAMPBELL, C. S.; KELLOGG, E. A.; STEVENS, P. F.; DONOGHUE, M. J. Sistemática vegetal: um enfoque filogenético. Porto Alegre: Artmed, 2009. p. 355-359.

MARCHIORI, J.N.C. Comprovação da viabilidade da utilização da secção longitudinal tangencial para a determinação histométrica dos elementos axiais do xilema secundário. In: Anais do IV Congresso Florestal Estadual, Nova Prata, RS, p. $180-184,1980$.

METCALFE, C.R.; CHALK, L. Anatomy of the Dicotyledons. Oxford: Clarendon Press, 1972. p. 404-413.

SCHULTZ, A. R. Introdução ao estudo da Botânica Sistemática. Porto Alegre: Livraria do Globo, 1943. p. 377-383.

SOUZA, V.C.; LORENZI, H. Botânica Sistemática: guia ilustrado para identificação das famílias de Angiospermas da flora brasileira, baseado em APG II. Nova Odessa: Instituto Plantarum, 2008. p. 358-368.

WHEELER, E.A.; BAAS, P.; GASSON, P.E. IAWA list of microscopic features for hardwood identification. IAWA Bulletin, v.10, n. 3, p. 218359, 1989. 